\title{
A ESCOLA: CONSTRUÇÃO SOCIAL, ACONTECIMENTO E COTIDIANO
}

\author{
Cristina Batista de Araújo*
}

\begin{abstract}
Resumo
O presente artigo trata de apresentar a escola como uma instituição social que, como tal, sofre as interferências do modelo de sociedade em que se insere e, por náo estar isenta, participa do processo de criação e manutenção de verdades e de produção de subjetividades. Igualmente, a escola é estudada como uma construção social passível de ser discursivizada e constituída por sentidos que se constroem e se manifestam, dentre outras formas, nas práticas cotidianas de interação e, por conseguinte, se estabilizam/desestabilizam à medida que os sujeitos os reiteram. Sendo assim, procurou-se suscitar a perspectiva discursiva da escola, captada durante alguns momentos do cotidiano do Centro de Ensino e Pesquisa Aplicada à Educação (Cepae/UFG), no decorrer do ano de 2006, que ressoaram seu caráter sócio-histórico, por mais singulares que fossem.

Palavras-Chave: cotidiano, ensino, análise do discurso.
\end{abstract}

\section{The school: social construction, event and quotidian}

\section{Abstract}

The present article presents the school as a social institution that suffers the interferences from the model of society where it is inserted and, since it is not immune, participates in the process of creation and maintenance of truths and in the production of subjectivities. Equally, the school is studied as a social construction constituted by meanings that are constructed and they reveal, among other forms, in quotidian practices of interaction and, therefore, they stabilize/(des) estabilize to the measure that the subjects reiterate them. In this way, it sought to give rise to the discursive perspective of the school, captured during some moments of the quotidian in Centro de Ensino e Pesquisa Aplicada à Educação (Cepae/UFG), in the year of 2006, that they had resounded its sociohistorical character, however singulars as they may sound.

KEY wORDS: quotidian, teaching, analysis of discourse.

\section{INTRODUÇÃo}

A escola é o lugar da disciplina, do aprendizado e do exercício. Sua função de formar o aluno e prepará-lo para o mundo reitera cotidianamente

* Mestre em Letras e Lingüística pela Faculdade de Letras da UFG. Professora da Escola Municipal Mônica de Castro Carneiro, na cidade de Goiânia. Pesquisadora do Grupo TRAMA/ UFG - Círculo Goiano de Análise do Discurso. E-mail: cristina_araujo1@yahoo.com.br. 
sua atividade disciplinar e evidencia sua prática controladora. As filas que os alunos fazem nos pátios das escolas, a disposição de carteiras numa sala de aula, a distribuição dos alunos conforme a idade ou séries e outros aspectos mais (d)enunciam um saber que qualifica. Além do mais, assim como outros dispositivos, a escola assume um caráter essencialmente necessário e produtivo, visto que as mais diversas açóes se encontram revestidas de poder sutil.

É preciso, pois, falar dela e fazê-la falar! Pode-se fazer isso pela perspectiva da educação maior (Deleuze apud Gallo, 2003), isto é, falar dela por meio das políticas públicas, das leis, dos seus parâmetros, daquilo que se realiza em gabinetes e se expressa em documentos. Mas pode-se fazer o mesmo através de outros lugares, dos atos cotidianos, da sala, daquilo que só é apreensível quando há disposição para lidar com situações de confronto e resistências, uma educação menor (Deleuze apud Gallo, 2003), que se expressa nas manifestaçóes dos sujeitos dispostos a fazê-la falar.

A possibilidade de olhar a escola e fazê-la falar por meio das açóes cotidianas permite a compreensáo do processo de construção dos sentidos atribuídos a ela, assim como admite a identificação de alguns aspectos que estejam contribuindo para a naturalização de alguns enunciados que circulam na escola e que são compartilhados por pais, alunos e até professores, muitas vezes constituindo-se em crenças. Nesse sentido, tratar-se-á de identificar algumas das formas pelas quais as pessoas descrevem, explicam ou dão conta desse universo escolar, incluindo a si mesmas, por meio do discurso.

Para isso, é necessário admitir que os termos em que o mundo é conhecido são construtos sociais e, portanto, tal conhecimento não é uma coisa que as pessoas possuem em suas cabeças, mas algo que constroem juntas, numa arena de negociaçóes onde os sentidos são disputados e se estabilizam/desestabilizam. O exercício, então, consiste em desconstruir noçôes profunda e culturalmente arraigadas.

Quando se emprega o termo desconstrução é para se referir ao trabalho necessário de reflexão que possibilita uma desfamiliarização com construçóes que se transformaram em crenças e, enquanto tais, colocam-se como grandes entraves para que outras possam ser construídas. O termo desfamiliarização foi eleito porque dificilmente desconstrói-se o que foi construído, antes, cria-se espaço para que novas construçóes convivam com as anteriores, numa contínua ressignificação, jamais acabada, visto que todas ficam impregnadas em componentes culturais. Nas palavras de Pêcheux (1969/1993, p. 77), 
tal discurso remete a tal outro, frente ao qual é uma resposta direta ou indireta, ou do qual ele "orquestra" os termos principais ou anula os argumentos. Em outros termos, o processo discursivo não tem, de direito, início: $\mathrm{o}$ discurso se conjuga sempre sobre um discursivo prévio, ao qual ele atribui o papel de matéria-prima, e o orador sabe que quando evoca tal acontecimento, que já foi objeto de discurso, ressuscita no espírito dos ouvintes o discurso no qual este acontecimento era alegado, com as "deformaçôes" que a situação presente introduz e da qual pode tirar partido.

Ora, a noção de negociação de sentidos poderia sugerir um sujeito sempre disposto a cooperar no processo de construçóes sociais, o que, sabese, não é o caso, pois se trata de uma relação de negociação de singularidades, o que, convenha-se, não é tão simples como possa parecer. O discurso, nessa dimensão, representa um momento de tensão e de risco, pois sua incompletude gera diferenças, uma disputa de poderes muitas vezes acirrada e violenta. Contornar esse risco implica decidir o que será preservado e reproduzido e o que, por meio de acordos, pode e deve ser transformado. Olhar a escola sob a perspectiva discursiva é, pois, tratar de tais processos considerando-se todas as suas implicaçôes: riscos, conflitos, diferenças, relaçôes de poder, construção e transformação de sentidos.

Sendo assim, os estudos que tomam a escola e suas relaçóes como objetos precisam explicitar os mecanismos pelos quais as práticas discursivas tornam evidente o que não é, e que resulta de espessos processos de produçáo de sentido historicamente estabelecidos, construídos em confrontos de relaçóes que são também sócio-historicamente fundadas e que se realizam num contexto, mas não se limitam a ele porque têm historicidade, têm passado e se projetam num futuro.

Nessa perspectiva, o discurso deve ser tratado como um acontecimento único que, apesar de contar com o suporte lingüístico necessário para sua existência, precisará estar relacionado à instância de sua enunciação, e uma vez considerado em uma instância de enunciação diferente da primeira, suscitará outra série de significações. Desse modo, conforme já mencionado,

é preciso estar pronto para acolher cada momento do discurso em sua irrupção de acontecimentos, nessa pontualidade em que aparece e nessa dispersão temporal que lhe permite ser repetido, sabido, esquecido, transformado, apagado até nos menores traços, escondido bem longe de todos os olhares, na poeira dos livros. Náo é preciso remeter o discurso à lon- 
gínqua presença da origem; é preciso tratá-lo no jogo de sua instância. (Foucault, 1995a, p. 28)

Para Foucault (1996), o acontecimento se define em relação à inscrição do que é dito em um momento determinado, constituído na mobilização de uma estrutura lingüística tratada em sua irrupção histórica. O acontecimento é, portanto, efetivado na materialidade e consiste na relação, na dispersão, no recorte e na seleção de enunciados. Ele abre a si mesmo uma existência no campo da memória; é único, mas se oferece à repetição, à reativação; está ligado tanto às situaçôes imediatas quanto aos enunciados que o precedem e o sucedem.

Analisar os discursos que circulam na escola acerca de seus elementos constituintes é inscrevê-los numa dimensão histórica, percorrendo descontinuidades enunciativas, mobilizando especificidades, buscando a dispersão de sua exterioridade. Sem, no entanto, tentar restituir ao já dito o instante paradoxal do segundo nascimento, sem invocar uma aurora prestes a retornar, mas tratá-los "na densidade do acúmulo em que são tomados e que, entretanto, não deixam de modificar, de inquietar, de agitar e, às vezes, de arruinar" (Foucault, 1995a, p. 144).

Procurando manter uma estreita relação entre os pressupostos epistemológicos e a abordagem teórica propostos até aqui, buscar-se-á compreender alguns dos sentidos que circulam na escola por meio de discursos de várias ordens que, tomados como acontecimentos discursivos e expressos por diferentes sujeitos dessa esfera social, ressoam o caráter histórico-dialógico e interdiscursivo das práticas sociais.

\section{AS PRÁTICAS SOCIAIS APREENDIDAS NO COTIDIANO}

O cotidiano é permeado pelas mais diversas formas de interação social e, por ser considerado corriqueiro, muitas vezes é desprezado como fonte de pesquisa e dificilmente se pensa na riqueza e nas peculiaridades que possam estar presentes nessa esfera. Conversar é uma das maneiras por meio das quais as pessoas produzem sentidos e se posicionam nas relaçóes estabelecidas no cotidiano que, por isso, são práticas discursivas, compreendidas como linguagem em ação. Se considerarmos a informalidade das situaçóes em que ocorrem, as conversas representam modalidades privilegiadas para o estudo da produção de sentidos. 
Bakhtin (1995), ao trabalhar com o conceito de parole numa perspectiva de produção coletiva e discutir a interação verbal, situa a conversação como algo extremamente rico e importante na arena da comunicação na vida cotidiana, vinculando-a aos processos de produção em geral, assim como às esferas das diversas ideologias. $\mathrm{O}$ autor lista algumas situaçóes típicas de conversas, enfatizando sua importância como prática social,

a psicologia do corpo social é justamente o meio ambiente inicial dos atos de fala de toda espécie, e é neste elemento que se acham submersas todas as formas e aspectos da criação ideológica ininterrupta: as conversas de corredor, as trocas de opinião no teatro e, no concerto, nas diferentes reuniôes sociais, as trocas puramente fortuitas, o modo de reação verbal face às realidades da vida e aos acontecimentos do dia-a-dia, o discurso interior e a consciência auto-referente, a regulamentação social, etc. A psicologia do corpo social se manifesta essencialmente nos mais diversos aspectos da "enunciaçáa" sob a forma de diferentes modos de discurso, sejam eles interiores ou exteriores. (Bakhtin, 1995, p. 42)

Para Bakhtin (1995, p. 114), a forma e os estilos da enunciação ocasional são determinados pela situação e pelos integrantes mais imediatos, já "os estratos mais profundos da sua estrutura são determinados pelas pressôes sociais mais substanciais e duráveis a que está submetido o locutor”. Assim, o trabalho com conversas pressupóe que se leve em consideração o conceito de enunciado, a tipicidade da situação e a inter-relação estabelecida entre o tempo curto da situação relacional e o contexto mais amplo de circulação das idéias.

O conceito de enunciado está inerentemente ligado ao conceito de voz e, deste modo, constitui-se em produto da fala. Conforme já discutido, para Bakhtin (1995) a fala (parole), que tem na enunciação o produto da interação entre falantes, não pode ser considerada como um ato individual estrito senso, mas de natureza social, expressa por meio de palavras e sentenças que se articulam em açóes situadas. Então, a voz é entendida como ponto de vista resultante da significação e/ou ressignificação de muitas outras vozes, e qualquer enunciado, por conseguinte, constitui-se em um dos elos de uma corrente de outros enunciados, complexamente organizados.

Portanto, "não há enunciado em geral, enunciado livre, neutro e independente; mas sempre um enunciado fazendo parte de uma série ou de um conjunto, desempenhando um papel no meio dos outros, neles se 
apoiando e deles se distinguindo" (Foucault, 1995a, p. 113-114). Por essa razão, o sujeito, ao formular um enunciado, certamente expressará seu horizonte conceitual e sua visão de mundo resultantes de suas relações constitutivas, não porque ele seja o princípio causador de tais relações, tampouco porque sua intenção significativa possa determinar o que ele quis dizer, mas porque há um lugar nessa enunciação que pode ser ocupado por diferentes indivíduos, e por isso a significação não permanece uniforme.

Ainda que se considere que a enunciaçáo tenha um autor - mesmo que seu enunciado esteja povoado de múltiplas vozes - e um interlocutor a quem esteja sendo direcionada, haverá sempre que considerar um duplo caminho que faz das práticas discursivas e, portanto, das conversas, um ato dialógico. Por outro lado, se se considerar um enunciado como constitutivo da função enunciativa (Foucault, 1995a), será preciso compreender qual a posição que pode e deve ocupar todo indivíduo para ser seu sujeito. Em qualquer uma dessas instâncias, o foco de estudo voltar-se-á para as especificidades que compóem uma conversa tanto em relação ao local de sua ocorrência, integrantes e contexto imediato da situação, quanto em relação à sua dimensão histórica que constitui não só o sujeito, mas também o acúmulo e a exterioridade do discurso.

Outro aspecto a ser considerado numa conversa está presente na própria noção de vozes e na idéia de que os enunciados são sempre elos de uma cadeia mais ampla de sentidos: trata-se da inter-relação entre o tempo da situação e o contexto mais amplo. Assim, as conversas, por mais específicas que possam ser em função de seu contexto imediato, estão permeadas pela dimensão histórica que suscita as construçóes sociais a que estáo submetidos seus integrantes.

Utilizar conversas do cotidiano como fonte de investigação significou estar em campo durante todo o tempo da pesquisa, de forma que sempre que surgia algum dos temas de interesse era necessário redobrar a atenção. Algumas situaçóes presenciadas acabaram se perdendo devido à dificuldade de registro (náo registrar durante a conversa ou logo em seguida, por exemplo). Em algumas das situaçóes, o registro foi feito de memória, pois o uso do gravador mostrou-se problemático, além de que algumas conversas eram tão fugazes que não havia tempo hábil para ligar o gravador. A dificuldade era minimizada quando os participantes da conversa auxiliavam nas anotaçóes ou quando essa conversa estava inserida nas aulas observadas. Em resumo, foi impossível padronizar a forma de registro; ela acompanhou o inesperado das situaçóes do dia-a-dia. 


\section{Conversando...}

As conversas que integram o corpus aqui analisado foram coletadas durante algumas aulas de português, aulas de coordenação e aulas na biblioteca de turmas da segunda fase do ensino fundamental do Centro de Ensino e Pesquisa Aplicada à Educação, durante o ano letivo de 2006. Além disso, foram registrados alguns momentos informais de conversas cotidianas entre diferentes sujeitos da escola.

O processo de análise das conversas cotidianas deu-se em duas etapas, a apresentaçáo de cada conversa, envolvendo o contexto situacional e os enunciados, e a síntese temática do conjunto das conversas e sua relação com o contexto mais amplo de circulação das idéias. O agrupamento das conversas foi, primeiramente, em função dos repertórios que possibilitaram enfocar a atribuição de um papel ou de uma posição a alguns sujeitos da esfera escolar, e que de alguma forma exercem influência na mobilização do enunciado e/ou no reconhecimento de subjetividades. Em seguida, foram agrupadas aquelas conversas que possibilitaram depreender os sentidos atribuídos aos saberes que são vinculados ao universo escolar, quer nas aulas de língua portuguesa, quer fora delas. No entanto, sabe-se que esses agrupamentos acabam por segmentar a leitura, apesar de alguns desses temas estarem inter-relacionados.

\section{Conversa 1}

1. Contexto da conversa: durante uma aula, a professora interrompe a explicação que está fazendo e se dirige a dois alunos.

2. Registro da conversa:

[1]

Professora: - Será que vocês vão continuar mesmo depois de tudo, depois de separados?

Aluno 1: - A gente não tá conversando!

Professora: - Ah, não, tá trocando uma idéia!

Aluno 1: - Oh, professora, não vou falar que é mentira sua, não, porque senão eu vou te desonrar, mas não é verdade não. A gente não tá conversando.

Nessa conversa, o que instaura o diálogo é a recorrência a um momento anterior a esse, cujo enunciado se presentifica nas formas "vocês vão continuar" e "depois de tudo". O dado anterior só se materializa quando 
o aluno diz o que não está fazendo e, dessa forma, é possível saber do que se trata; além disso, antes da fala da professora a atitude dos dois alunos não fora notada pelos demais. Quando esse aluno nega que estava violando algo previamente combinado suscita a significação do que era estável, conversar e trocar uma idéia passam a ter o mesmo valor: uma infração. Diante disso, ao ter que argumentar com a professora, ele desloca o foco da infração para uma pseudo-moral, pois dizer que o professor mente tratar-se-ia de uma "desonra", mas, utilizando o mesmo recurso da negação, ele póe em xeque a sua verdade com a da professora: “- Mas não é verdade não”. Ao espectador resta a dúvida: afinal, o aluno, ao dizer: “- A gente não tá conversando", negou que estava conversando no sentido de atrapalhar ou como o simples ato de falar?

\section{Conversa 2}

1. Contexto da conversa: Início de uma aula de português.

2. Registro da conversa

[2]

Professora: - Gente, peguem aí a folha da aula passada, pra gente ler...

Aluno 1: - Eu náo gosto de ler livro de terror... nem de suspense.

Aluno 2: - Prefiro um livro de fatos, de coisas reais.

Professora: - Ler isso também é importante e tem outra função. E pra quê serve a literatura? Primeiro que eu acho que nem todo mundo leu... ((Nesse momento alguns alunos começam a falar quase ao mesmo tempo e só dá pra entender algumas intervençóes da professora))

Aluno 3: - Essa aula é muito chata!

Professora: - Vocês estão muito no mundo real... a literatura não tem que ser real. Vocês estão pensando só na verdade.

Aluno 1: - Mas um filme não cansa, ler isso cansa.

Aluno 2: - É, cansa mesmo, um texto desse tamanho!

Aluno 4: - Ah, professora, e esse final é muito chato, nada a ver...

Professora: - Vamos fazer assim, já que vocês estão achando o final sem graça, vamos escrever um final pra ele!

Alguns alunos: - Não, não! Ah, professora, tem graça não!

- Você quer é um livro de 60 páginas?!!

- A culpa é da Fulana que reclamou do fim do conto!

Professora: - Não, gente! Não é culpa de ninguém. Eu ia pedir pra vocês fazerem mesmo, é que eu aproveitei que vocês reclamaram mesmo.

Aluno 4: - Não sei que que vocês tinham que reclamar! 
Por mais que essa conversa tenha trazido um conflito referente aos objetos de ensino (a leitura e a leitura de ficção), o que se destaca é a relação que os alunos fazem do gostar/não gostar do texto com a responsabilidade que a professora tem de promover uma aula. É como se eles acreditassem que a aula era uma proposta e que, diante disso, eles poderiam aceitar ou recusar, manifestando tais sentimentos em suas reclamaçóes. A primeira tensão gira em torno do tipo de leitura a ser feita, e distinguem fatos e coisas reais de algo que eles chamam de terror e de suspense e que a professora nomeia literatura. Em seguida, polemizam com o texto em questão caracterizando-o como cansativo e chato. Observe-se o percurso: "Essa aula é muito chata", "Ler isso cansa", "Esse final é muito chato". Sob a alegação de que não estariam gostando apenas do final, a professora propóe outra atividade: “- Já que vocês estão achando o final sem graça, vamos escrever um final pra ele!” Mas a reação é o tumulto, pois a nova proposta soa como punição por terem reclamado: "- A culpa é da Fulana que reclamou do fim do conto". Por fim, percebe-se que algumas regularidades discursivas aparecem apesar de não serem tratadas explicitamente; uma é que não basta reclamar, cada um tem que fazer sua parte ("Primeiro que eu acho que nem todo mundo leu"); outra é que mesmo tendo do que reclamar em algumas circunstâncias é melhor não fazê-lo ("Não sei que que vocês tinham que reclamar!").

\section{Conversa 3}

1. Contexto da conversa: Durante uma aula de português a professora escreve no quadro: "Maria toma banho quente e sua mãe diz ela quero banho frio", e desafia os alunos a colocarem a pontuaçáo nessa frase de modo que ela faça sentido. Diz que dará um conceito A pra quem conseguir realizar a tarefa primeiro. Alguns alunos que estão sentados próximos à pesquisadora fazem um alvoroço.

2. Registro da conversa:

Aluno 1: - Faz pra mim, professora.

Pesquisadora: - Mas eu ainda estou pensando.

Aluno 2: - Aceita suborno?

((Sorrio e nada respondo))

((Um dos alunos apresenta o caderno à professora, os demais esperam para ver se ele acertou, mas como não estava certo os colegas vaiam. Depois de 


\section{Revista Solta a Voz, v. 19, n. 2}

um certo tempo, a professora decide suspender a proposta, já que ninguém conseguira))

Professora: - Olha, é preciso ver o sentido das palavras, ir analisando de uma por uma, e ver qual delas pode ter mais de um sentido, que pode ser empregada de mais de uma forma.

((Ela vai fazendo essa análise palavra a palavra com os alunos até que chega à palavra sua, mostra que nesse caso trata-se do verbo suar.))

Aluno 2: - Você sabia?

Pesquisadora: - Não.

Aluno 2: - Você não serve pra ser professora de português, não...

Pesquisadora: - Ué, mas por quê?

Aluno 2: - Você não conseguiu adivinhar esse aí!

Aluno 1: - Num serve nem pra dá cola...

Aluno 2: - Mas eu num tô nem aí, C pra mim já tá bom.

De uma forma bem concisa, a conversa acima revela a crença de que o professor é aquele que deve dominar todos os saberes possíveis referentes ao seu campo de saber, inclusive os que possam parecer enigmáticos: "Você não serve para ser professora de português [...] você náo conseguiu adivinhar esse aî". Do mesmo modo, depreende-se que deter um saber pode ainda valer para outras coisas; o saber pode ser moeda para se conseguir algo: "Faz pra mim" e "aceita suborno?". Tais enunciados apontam para o fato de que se há incapacidade para fazer alguma coisa específica pode-se recorrer àquele que tem a capacidade necessária negociável. Assim, o saber do professor é tanto aquilo que o legitima na função quanto o que pode ser barganhado com quem não o tem, mas o quer.

\section{Conversa 4}

1. Contexto da conversa: Depois de dez minutos que a aula havia começado uma aluna chega à porta da sala, faz acenos pedindo para entrar, também com acenos a professora indica o relógio e não permite sua entrada. Alguns alunos que estavam dentro da sala e que viram a cena interferem na situação.

2. Registro da conversa:

[4]

Aluno 1: - Deixa, professora!

((outros colegas vêem a aluna de fora, que até então não fora percebida)) 
Alunos: - Não pode, não pode!

Aluno 2: - É. Vai pra coordenação.

Professora: - Pra coordenaçáo não, vai ficar aí de fora.

Aluno 1: - Ah, professora! Você é boazinha!!

Aluno 2: - A de geografia já dá logo uma advertência... (incompreensível) manda pra coordenação.

Aluna 3: - Você é boazinha!!

Professora: - É. Eu sou boazinha.

Nessa conversa, o fato de a aluna chegar atrasada à aula mobilizou uma situação de tomada de decisão pautada por algumas regras, não explicitadas, mas provavelmente conhecidas pelos envolvidos. $\mathrm{O}$ primeiro aluno a se manifestar pareceu, à primeira vista, solidário com a colega: “- Deixa, professora!", enquanto que outros reforçaram o fato de não poder entrar, de ter que adotar um procedimento aparentemente padrão: “- Não pode, não pode", “- É. Vai pra coordenaçáo”. Ao não seguir tal procedimento, a professora recebe a reprovação visível desse grupo, que a compara com outra professora, para dizer que além de não fazer o mínimo que deveria está sendo pouco rigorosa: “- Ah, professora! Você é boazinha!!”. Pode-se presumir que tal reprovação já estivesse presente desde a fala do primeiro aluno, uma vez que, ao pedir à professora que deixasse a aluna entrar, ele não só se solidariza com a colega como também age contrariamente ao posicionamento da professora. Essa parece ser uma situação em que qualquer das decisóes da professora ocasionaria algum comentário: se não é rígida, é boazinha.

\section{Conversa 5}

1. Contexto da conversa: Eu estava sentada na biblioteca enquanto aguardava para entrar em uma das turmas onde fazia observação. Uma funcionária pergunta se sou professora substituta ou estagiária, respondo que estou fazendo mestrado e desenvolvo ali minha pesquisa de campo.

2. Registro da conversa:

[5]

Funcionária: - Sua pesquisa é sobre o quê?

Pesquisadora: - Eu pesquiso como se aprende e como se ensina português na escola; como que a nossa própria língua, que a gente usa a todo momento, pode ser algo estranho e às vezes até difícil. 
Funcionária: - Ah. (pausa) Eu sempre fui mal em português.

Pesquisadora: - É. Como assim?

Funcionária: - Pra mim, o mais importante é aprender a ler. E essa é a minha maior falha, eu não fui bem alfabetizada, e quando eu fazia a primeira série mudei pro Piauí. Quando cheguei lá, eu era a mais adiantada da sala e falava muito bem, aí a professora chamou minha máe e disse que ia me passar pra terceira série. O problema é que eu voltei pra cá e reprovei na quarta série. $\mathrm{O}$ ensino lá era muito fraco, aí aconteceu que eu nunca fui alfabetizada mesmo, de verdade. Por causa disso eu sempre tive dificuldade na escola, a minha vida inteira.

Da conversa acima se destaca basicamente a imagem que se tem da língua, ressaltada por sua associação à dificuldade. Em alguns momentos a língua se resume a um objeto, que é "aprender a ler", e aparece como algo externo, que se confunde com a disciplina escolar: "- Eu sempre fui mal em português", "Eu nunca fui alfabetizada mesmo". Em outro momento a língua aparece vinculada ao uso: "- Eu falava muito bem". Segundo a própria funcionária, o problema foi ter queimado etapas no esquadrinhamento escolar, porque no ensino fraco fora classificada apta a avançar séries, mas, depois, o ensino forte mostrou-lhe que, "de verdade", ela precisaria ficar retida. Prováveis mostras de que o ensino não seja tão padronizado e coerente como queira parecer, é como se ela dissesse "o que supervalorizaram lá, desconsideraram aqui”, e em função disso assumiu para si toda a responsabilidade por sua "falha" escolar: "eu sempre fui", "eu nunca fui", "eu sempre tive".

\section{Conversa 6}

1. Contexto da conversa: Durante o recreio, alguns alunos permanecem na sala conversando sobre uma decisão tomada no Conselho de classe. A conversa vai atraindo alguns outros colegas que vão se achegando para saber do que se trata.

2. Registro da conversa:

[6]

Aluno 1: - Eu não acho que tinha que chamar a família dele, não.

Aluno 2: - Eu também não. Eu acho que se acontece alguma coisa aqui comigo, tem que resolver é comigo, num é com ninguém da minha família, não. Aluno 3:- Mas eu acho que nem sempre dá pra resolver só aqui com aluno. 
Pesquisadora: - O que foi que aconteceu?

Aluno 2: - A professora de História, lá no Conselho, mandou chamar alguém da minha família aqui. Disse que se não vier ninguém eu não assisto mais a aula.

Aluno 3: - É, mais tá certo... igual, eu estudei numa escola que os alunos quando faziam coisa errada, aí chamava a família, tentava entender a família dele... sei lá, por que a família influencia muito, por exemplo, se os pais são separados, isso vai refletir na escola. O certo é que a escola tem que fazer um acompanhamento pra saber se ele tem algum problema na família, sei lá, fazer um acordo com a família pra... conciliar o que ele vai fazer em casa e o que ele vai fazer na escola.

Pesquisadora: - No conselho de classe, em algum momento conversa sobre essa questão da família?

Aluno 1: - Não. Só quando tem algum problema.

Aluno 1: - Professora, eu quero aproveitar e responder um negócio pra Fulana. Eu tenho uma família que é toda complicada, meu pai é doido, minha mãe morreu, minha vó cuida de mim, e é...super assim... sabe, tipo assim, eu não morri até hoje, não sou anormal, não tenho um parafuso a menos por causa dessas coisas. Sou brigona? Sou. Tenho defeitos? Tenho. Mas eu não sou uma pessoa difícil de conviver... só quem não gosta de mim. Não é porque a família é doida, imperfeita. Ela pode também servir de exemplo, tipo, meu pai é de uma maneira, eu não quero ser igual a ele, pô cara, eu não vou ser, então... sabe, num é porque a família é de um jeito significa que eu tenho que ser igual.

Essa conversa traz à tona algumas das regularidades referentes aos mecanismos de controle utilizados pela escola no processo de produçáo de subjetividades. Partindo da premissa de que a escola objetiva fabricar um tipo específico de sujeito, é comum que ela procure estratégias que possam reforçar suas verdades em outras instâncias, como no caso de se chamar a família à escola. No entanto, como todo projeto de poder pressupóe resistências, nota-se que não há consenso, entre os alunos, no uso de tal estratégia, que marcam seus posicionamentos de uma forma bem lúcida. Quando dizem: "- Se acontece alguma coisa aqui comigo, tem que resolver é comigo", há uma recusa em ser tomado como alvo de olhares e como objeto de uma discussão que, apesar de ser sobre ele, o exclui. Outro aluno parece fazer o contraponto com os discursos do poder: "- Nem sempre dá pra resolver só aqui com o aluno", e como se estivesse rendido a esse discurso afirma que a escola deve "fazer um acordo com a família pra conciliar o que ele [o aluno] 
vai fazer em casa e o que vai fazer na escola”. Aparece, ainda, na fala desses alunos a vinculação que se faz do sujeito ao seu meio; é que ele reproduzirá aquilo que vê ou aquilo que vive: “- se os pais são separados, isso vai refletir na escola”. Mas há outra contestação muito veemente que, por meio de um exemplo próprio, conclusivamente tenta desmontar a tese anterior: "- Num é porque a família é de um jeito significa que eu tenho que ser igual”.

\section{Conversa 7}

1. Contexto da conversa: Durante uma entrevista com um grupo de quatro alunos.

2. Registro da conversa:

[7]

Pesquisadora: - O que vocês acham que deveria ser trabalhado nas aulas de português?

Aluno 1: - Redação, professora. Tem que treinar ler e escrever.

Aluno 2: - Ah, sei lá... isso já tá muito batido, tem que ser uns tema assim que nem violência, drogas, assassinatos..., essas coisas que acontecem no dia-a-dia.

Pesquisadora: - Vocês concordam?

((alguns respondem afirmativamente))

Aluno 3: - Tem também, assim... fatos históricos, né?

Aluno 4: - Isso é em história.

Aluno 3: - Não, se for fatos do passado, é em história, mas coisa do presente pode ser sim em português.

Alunos 1:-É.

Aluno 2: - Então. Pode ser fatos do mundo, no geral, essas coisas que tâo acontecendo, guerras, tragédias, na política...

Pesquisadora: - Ah, entendi.

Aluno 4: - Ô professora, tem uma coisa.

Pesquisadora: - O quê?

Aluno 4: - Tem que ser umas aula mais chamativa.

Pesquisadora: - Como é que é uma aula chamativa?

Aluno 3: - Assim... Eu vou falar primeiro uma não chamativa. Aula não chamativa é com umas tarefas mais normal, tipo que a professora passa dela mesma, mas... agora, se não tiver a opiniâo dos alunos, o que eles gostam, não vai chamar a atenção dos alunos e a professora vai ficar falando e ninguém vai prestar atenção porque náo prende a atenção das pessoas e ela vai falar em vão... 
Pesquisadora: - E o que você acha?

Aluno 1:- Uma aula não chamativa é uma aula que só tem texto, ou então quando um professor fala, fala, fala...

Aluno 3: - É. E você num pode nem participar... assim... ele dá a explicação dele mas... eu, não gosto de professor que fala muito não, entende... Pesquisadora: - E quem seria o responsável por uma aula chamativa? Aluno 2: - O maior responsável é o aluno porque é ele que vai participar ou não...

Aluno 4: - Na verdade mesmo, é dos dois, só que mais do aluno porque ele é que vai propor uma aula chamativa e aí o professor percebe que ele tá interessado e faz.

Pesquisadora: - No caso de uma aula de português, o que faz com que ela seja chamativa?

Aluno 2: - Debate com a opiniáo dos alunos, textos sobre coisas interessantes...

Pode-se depreender da seqüência de conversas acima que os saberes e os objetos de ensino fazem parte do imaginário que os alunos constroem do que se deve estudar na escola. Enquanto reivindicam as "coisas da atualidade" como assuntos a serem estudados parecem não se dar conta de que todas elas perpassam pela linguagem, por aquilo que o aluno sintetizou em: "- Tem que treinar ler e escrever", o que o colega logo rechaçou: "- Isso tá muito batido". Ao que parece, os alunos associam o que se deve estudar com uma interação possível entre a escola e o mundo, afastando a noção de que os objetos de ensino devam permanecer alheios ao cotidiano e suas práticas. A reivindicação mais incisiva recai na forma como tais saberes serão trabalhados, em outras palavras, no trabalho pedagógico. E nesse sentido o aluno é enfático: “- Tem que ser umas aula mais chamativa”. Quando chamados a explicar como seriam essas aulas, os alunos apresentam o desejo de participar no processo de construção, associam isso a "deixar o aluno dar a sua opinião" e "náo ficar falando o tempo todo".

\section{SABERES E SUJEITOS}

No decorrer deste trabalho, foi possível ver que as conversas cotidianas, os diversos enunciados, constroem um discurso muito particular que, em certa medida, expressa o que os sujeitos escolares compreendem sobre si próprios, sobre a escola e sobre o saber específico de uma disciplina. Viu- 
se, ainda, que há um espaço em que os sujeitos podem tomar posição para falar dos objetos de que se ocupam em seu discurso, assumindo, portanto, a função de sujeito enunciador de um discurso, capaz de acionar as várias relaçôes que um enunciado suscita.

Alguns aspectos suscitados neste artigo, referentes ao saber, ao sujeito e à sociedade, reforçam a idéia de que o ensino, a escola e a aula de português podem ser tratados como um conjunto de práticas discursivas que resultam de uma ação histórica, como um evento singular que é transformado por seus atores cotidianamente, como um palco para as encenaçóes dos modelos de organização social. É possível, ainda, afirmar que existe uma correlação entre os saberes instituídos em função de uma vontade de verdade, os sujeitos que se apropriam dos discursos produtores de subjetividades e a fabricação de um contexto sócio-histórico condizente com as finalidades pretendidas.

Nesse sentido, as conversas vistas no tópico anterior são exemplos do movimento de coexistência e seleçáo de saberes que, por sua vez, estabelecem instâncias de verdades para determinados sujeitos. Além disso, demonstram a eficiência dos procedimentos disciplinares que definem o dizível sobre a escola e seus atores, e o modo como os sujeitos devem pensar e se reconhecer nesses domínios. Entretanto, é preciso considerar que há efeitos que escapam à intencionalidade do poder (Dreyfus e Rabinow, 1995) e que os sujeitos não estão passivos às açôes, antes, eles operam com as táticas, dentro do campo de visão do outro,

aproveita as "ocasiōes" e delas depende, sem base para estocar benefícios, aumentar a propriedade e prever saídas. $\mathrm{O}$ que ele ganha não se conserva. Este não-lugar lhe permite sem dúvida mobilidade, mas numa docilidade aos azares do tempo, para captar no vôo as possibilidades oferecidas por um instante. Tem que utilizar, vigilante, as falhas que as conjunturas particulares vão abrindo na vigilância do poder proprietário. Aí vai caçar. Cria ali surpresas. Consegue estar onde ninguém espera. É astúcia. Em suma, a tática é a arte do fraco. (Certeau, 1994, p. 100-101)

Não se pode esquecer, ainda, que a resistência é inerente ao poder, e não se pode afirmar que o fato de o poder estar em toda parte exclui quaisquer formas de resistências. A relação entre poder e resistência pode ser analisada como duas faces de uma mesma moeda, já que o poder carece 
da resistência para existir, que por sua vez é uma das condições indispensáveis para que o poder se dissemine nas relações sociais (Foucault, 1988, 1995b, 2006). Portanto, não é de se estranhar que tais conversas revelam ora o que já se espera de qualquer discurso sobre o ensino, a escola, o aluno ou o professor, ora aspectos muito inusitados que demonstram rejeição à possibilidade de quaisquer formas de homogeneização.

\section{REFERÊNCIAS}

BAKHTIN, M. Marxismo e filosofia da linguagem. Trad. de Michel Lahud e Yara Frateschi Vieira. São Paulo: Hucitec, 1995.

CERTEAU, M. A invenção do cotidiano: 1. artes de fazer. Trad. de Ephraim Ferreira Alves. Petrópolis, Rio de Janeiro: Vozes, 1994.

DELEUZE, G. Conversaçôes. Trad. de Peter Pál Pelbart. Rio de Janeiro: Editora 34, 1992.

DREYFUS, H. L.; RABINOW, P. Michel Foucault, uma trajetória filosófica: para além do estruturalismo e da hermenêutica. Trad. de Vera Porto Carrero. Rio de Janeiro: Forense Universitária, 1995.

FOUCAULT, M. História da sexualidade: a vontade de saber. Trad. de Maria Thereza da Costa Albuquerque e J. A. Guilhon Albuquerque. Rio de Janeiro: Edições Graal, 1988.

. A arqueologia do saber. Trad. de Luiz Felipe Baeta Neves. Rio de Janeiro: Forense Universitária, 1995a.

. O sujeito e o poder. In: DREYFUS, H. L. e RABINOW, P. Michel Foucault, uma trajetória filosófica: para além do estruturalismo e da hermenêutica. Trad. de Vera Porto Carrero. Rio de Janeiro: Forense Universitária, 1995b.

. A ordem do discurso. Trad. de Laura Fraga de Almeida Sampaio. São Paulo: Ediçôes Loyola, 1996.

- Estratégia, poder-saber. 2. ed. Organização e seleção de textos, Manoel B. da Motta; trad. de Vera Lúcia Avellar Ribeiro. Rio de Janeiro: Forense Universitária, 2006. 


\section{Revista Solta a Voz, v. 19, n. 2}

GALLO, S. Deleuze e a educação. Belo Horizonte: Autêntica, 2003.

PÊCHEUX, M. Análise automática do discurso (AAD-69). In: GADET, F.; HAK, T. (Orgs.) Por uma análise automática do discurso: uma introdução à obra de Michel Pêcheux. Trad. de Bethânia S. Mariani et al. Campinas: Editora da Unicamp, 1993.

Recebido em: 27 out. 2008 Aceito em: 30 nov. 2008 